\title{
O DISCURSO DA INTERNACIONALIZAÇÃO ATRÁVES DE AULA-EVENTO
}

\author{
THE DISCOURSE OF INTERNATIONALIZATION THROUGH \\ THE CLASS EVENT
}

\author{
Henrique Almeida Santos ${ }^{1}$
}

Carina Merkle Lingnau ${ }^{2}$

\begin{abstract}
RESUMO
A internacionalização é um movimento global que tem ocupado vários espaços no mundo contemporâneo. Um desses espaços é a universidade, especificamente os cursos de graduação e pós-graduação. Na Universidade Tecnológica Federal do Paraná, campus Francisco Beltrão (UTFPR-FB) não foi diferente, com a inserção de editais de mobilidade estudantil internacional, duplo diploma, entre outros, o curso de Licenciatura em Informática também se interessou pela oportunidade de cursar parte da graduação no exterior e assim desenvolveu uma aula-evento junto à disciplina de Comunicação Linguística. Para desenvolver essa pesquisa buscamos em Michel Foucault a fundamentação teórica e analisamos a posição sujeito de dois palestrantes envolvidos na chamada aula-evento. Como resultados verificamos que um dos palestrantes assumiu a posição de sujeito acadêmico durante grande parte de sua fala, o que demonstra que em sua experiência vivenciou mais a relação universitária, enquanto o outro palestrante analisado se mostrou dividido em sua função sujeito, por vezes se posicionou como acadêmico, por outras assumiu a função profissional engenheiro ambiental que receberia uma oportunidade de trabalho na Europa.
\end{abstract}

Palavras-chave: Posição sujeito. Globalização. UTFPR.

\begin{abstract}
Internationalization is a global movement that has occupied various spaces in the contemporary world. One of them is the university, specifically undergraduate and postgraduate courses. At the Federal Technological University of Paraná, Francisco Beltrão campus (UTFPR-FB) was no different, with the insertion of international student mobility, double diploma, among others, the Computer Science Degree course was also interested in the opportunity to attend part of the program abroad and thus developed a class- event with the discipline of Linguistic Communication. To develop this research we sought in Michel Foucault the theoretical foundation and analyzed the subject position of we analyzed the subject position of two speakers involved in the so-called class-event. As a result, we verified that one of the speakers assumed the position of academic subject during most of his speech, which demonstrates that in his experience he experienced the university relationship more, while the other analyzed speaker was divided in his subject function, sometimes positioned himself as an academic, for others he took on the professional role of environmental engineer who would receive a job opportunity in Europe.
\end{abstract}

Keywords: Subject position. Globalization UTFPR

\footnotetext{
${ }^{1}$ Graduando em Licenciatura em Informática. Universidade Tecnológica Federal do Paraná, campus Francisco Beltrão (UTFPR-FB). E-mail: hensan.al@hotmail.com, Orcid: https://orcid.org/0000-0001-6017-9151. Lattes: http://lattes.cnpq.br/9171828724398346.

2 Doutora em Letras. Professora de magistério superior na Universidade Tecnológica Federal do Paraná, campus Francisco Beltrão (UTFPR-FB). E-mail: carinadebeltrao@gmail.com, Orcid:_https://orcid.org/0000-0002-8469-3961,_Lattes:_http://lattes.cnpq.br/2891086165049465.
} 


\section{Introdução}

O discurso da internacionalização está ficando cada vez mais presente nas instituições de ensino superior (IESs). Dentro desta perspectiva e participando desse momento histórico, os/as acadêmicos/as do curso de Licenciatura em Informática da Universidade Tecnológica Federal do Paraná, campus Francisco Beltrão (UTFPR-FB) todos os semestres precisam trabalhar a oralidade de alguma forma, através de palestra, evento, seminário etc. Desse modo, no segundo semestre de 2018 a turma foi questionada sobre o assunto que tinha interesse em desenvolver na parte oral da disciplina.

Depois de discutirem no grande grupo, chegaram a um consenso e decidiram por realizar um evento que mais tarde nomearam de aula-evento para a disciplina de Comunicação Linguística. Após optarem pela aula-evento fizeram uma votação para decidirem o tema gerador do evento e a escolha foi pelo assunto: internacionalização nos cursos das IESs. Desse modo, foram orientados a elaborar um evento durante um dos encontros da disciplina que somavam duas aulas.

Assim, a partir desta aula, que foi nomeada de aula-evento, um dos acadêmicos transformou essa atividade de extensão em material de análise para um semestre de iniciação científica voluntária na UTFPR-FB em que se utilizou do teórico Michel Foucault em sua análise do discurso (AD) para trazer algumas contribuições para a análise.

Desde 1960 a análise do discurso contribui significativamente de forma multidisciplinar com várias ciências. No Brasil a internacionalização é exemplo de discurso que em prática tem o objetivo de: elevar o nível das instituições de ensino, proporcionar imersões culturais, e um desenvolvimento científico, educacional e econômico do país através de parcerias internacionais com mobilidade estudantil, intercâmbios e duplas diplomações de alunos, professores globalizados no âmbito universitário que consiga acolher alunos e professores estrangeiros de forma natural e receptiva, integrando-os sem dificuldade. É necessário pessoas com conhecimentos linguísticos voltados ao inglês e demais idiomas para realizar parcerias com universidades no exterior e para realizar trocas de acadêmicos entre os países, independente das condições financeira de cada aluno, e que possa estudar cada realidade de forma particular.

Assim, o objetivo desse artigo é analisar a posição sujeito de dois palestrantes convidados para compartilhar suas experiências de mobilidade acadêmica no exterior a partir da AD foucaultiana. Para tanto, o artigo proposto se organiza da seguinte forma: primeiramente trataremos sobre a internacionalização, depois sobre a aula-evento, então discutiremos a metodologia utilizada, mostraremos os resultados e análises para finalizarmos com as considerações finais e referências. 


\section{Internacionalização na UTFPR-FB}

O campus da UTFPR-FB é uma instituição recente enquanto universidade, pois tem sua origem anterior no Centro Federal de Educação Tecnológica do Paraná (CEFET-PR). Por volta de 2008 foi iniciado o primeiro curso de graduação: Tecnologia de Alimentos. A partir dali vieram os outros cursos de graduação e pós-graduação. Atualmente o campus possui os seguintes cursos de graduação: Engenharia Ambiental, Engenharia de Alimentos, Engenharia Química e Licenciatura em Informática. Na pósgraduação a UTFPR-FB oferece como alternativa de estudos o Programa de Pós-Graduação em Engenharia Ambiental (PPGEA) e o Programa de Pós-Graduação em Tecnologia de Alimentos (PPGTAL). Eventualmente o campus proporciona cursos de especialização à comunidade.

A internacionalização começou a ser efetivada no campus com o advento do Programa federal Ciência sem Fronteiras, por volta de 2012 iniciou-se a geração de convênios entre IESs estrangeiras e UTFPR, além de convênios específicos entre universidades do exterior e a UTFPR-FB. Em termos gerais a internacionalização foi se tornando cada vez mais presente em editais e no mercado de trabalho.

Em termos conceituais tomamos de Morosini (2017, p.115-118) a discussão sobre internacionalização. A autora afirma que a:

[...] internacionalização da educação superior é um conceito complexo, com uma diversidade de termos relacionados, apresentando diversas fases de desenvolvimento. São citadas: a) dimensão internacional - presente no século XX, que se caracteriza por ser uma fase incidental mais do que organizada; b) educação internacional - atividade organizada prevalente nos Estados Unidos, entre a segunda guerra mundial e o término da guerra fria, preferentemente por razões políticas e de segurança nacional; e c) internacionalização da educação superior, posterior à guerra fria e com características de um processo estratégico ligado à globalização e à regionalização das sociedades e seu impacto na educação superior [...] Entretanto as discussões sobre a concepção de internacionalização universitária já não apresentam o caráter amplo do período anterior (2000 - 2003) e abarcam temas como internacionalização e as instituições universitárias. Isto porque, dada como certa a internacionalização, o pensamento mundial isomórfico passa a discutir os efeitos da globalização sobre a instituição universitária.

Desse modo, partimos desse conceito para analisarmos as questões relacionadas à internacionalização entre as instituições de ensino superior (IESs). Já que como Morosini (2017) aponta a internacionalização perpassa o mercado e a globalização que atravessam a educação internacional a partir das necessidades e verdades criadas por este tempo histórico.

\section{Aula-evento no curso de licenciatura em informática}

O curso de Comunicação linguística é oferecido no primeiro semestre da grade curricular do curso de graduação de Licenciatura em Informática. Essa disciplina possibilita o desenvolvimento de duas habilidades: a escrita e a oralidade. No quesito oralidade os/as acadêmicos/as do primeiro semestre desse curso em 2018.2 optaram por realizar um desafio: elaborar um evento, que mais tarde foi denominado de aula-evento. 
Normalmente os alunos que cursam essa disciplina preferem elaborar seminários por ser mais prático e mais aliado à rotina da academia. Esse grupo, no entanto, ao encarar o desafio de preparar uma aulaevento deixou de lado o que normalmente já realizava para enfrentar uma atividade cooperativa que oportunizou as qualidades individuais e coletivas. Para isso acontecer, no processo de orientação foram elaborados grupos de trabalho que se dividiram mediante as seguintes tarefas:

$\checkmark$ Grupo 1 - Momento do café: responsável pelo momento do momento de confraternização para comer e/ou beber algo após o evento;

$\checkmark$ Grupo 2: responsável pelo serviço de arrumação do ambiente (equipamentos, microfone, verificar as necessidades do/s orador/es - computador, projetor, quadro, espaço para o orador/es do evento, espaço para momento do café, capacidade do local - cadeiras, sonoridade, ventilação);

$\checkmark$ Grupo 3: responsável pela divulgação do evento;

$\checkmark$ Grupo 4: responsável pela organização dos oradores e tipo de evento;

$\checkmark$ Grupo 5: responsável pela organização das inscrições do evento (google docs, lista de presença para o dia do evento, outra forma de inscrição, pesquisa de satisfação do evento - online, papel ou outro modo de pesquisa);

$\checkmark$ Grupo 6: responsável pela organização da emissão dos certificados;

$\checkmark$ Grupo 7: responsável pela decoração do evento: para a mesa, porta ou outro;

$\checkmark$ Grupo 8: responsável pela organização do cerimonial;

$\checkmark$ Grupo 9 - responsável pela musicalização do ambiente e máquina de café;

$\checkmark$ Todos juntos: arrumação do local pós-evento: organização das cadeiras, retirada do lixo, desligamento dos equipamentos, apagamento das luzes - todos.

Como resultado do esforço realizado por estes grupos de trabalho para a materialização desta aula-evento temos como amostra as figuras abaixo:

Figura 1- Banner da aula-evento Mobilidade Estudantil Internacional

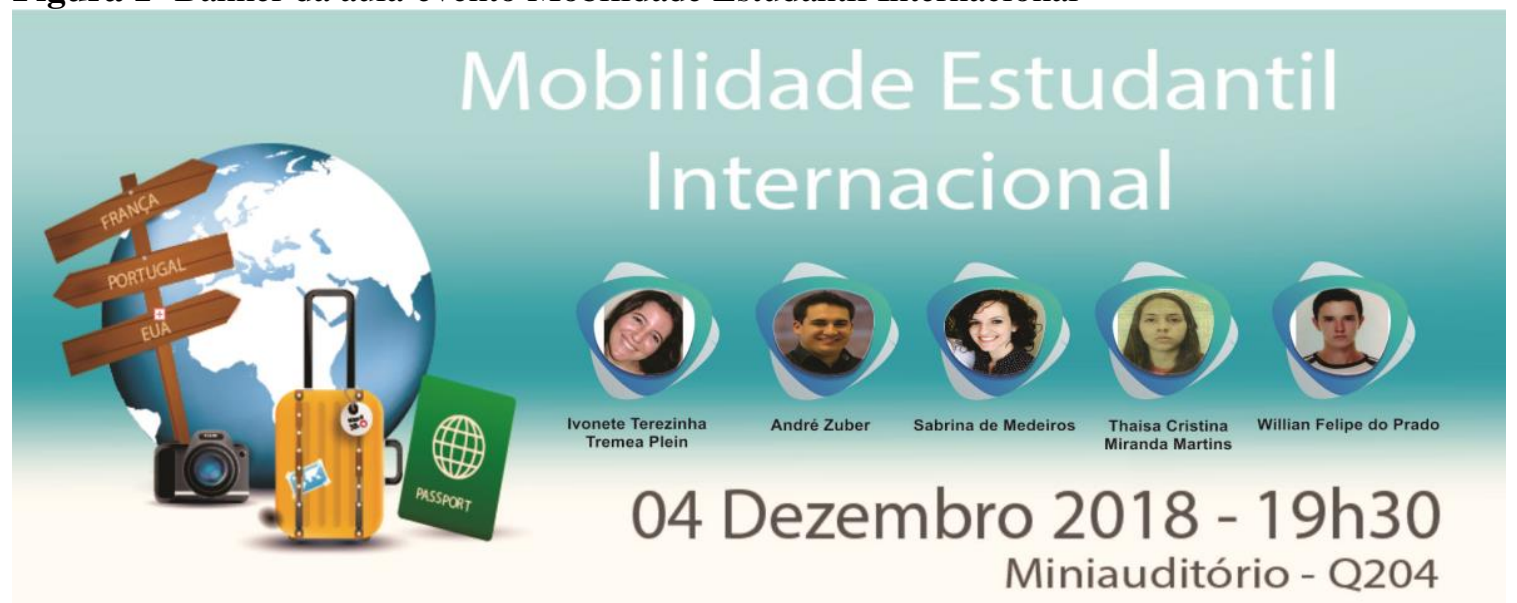

Fonte: grupo 3 - divulgação de eventos (2018). 
Figura 2: Música na aula-evento

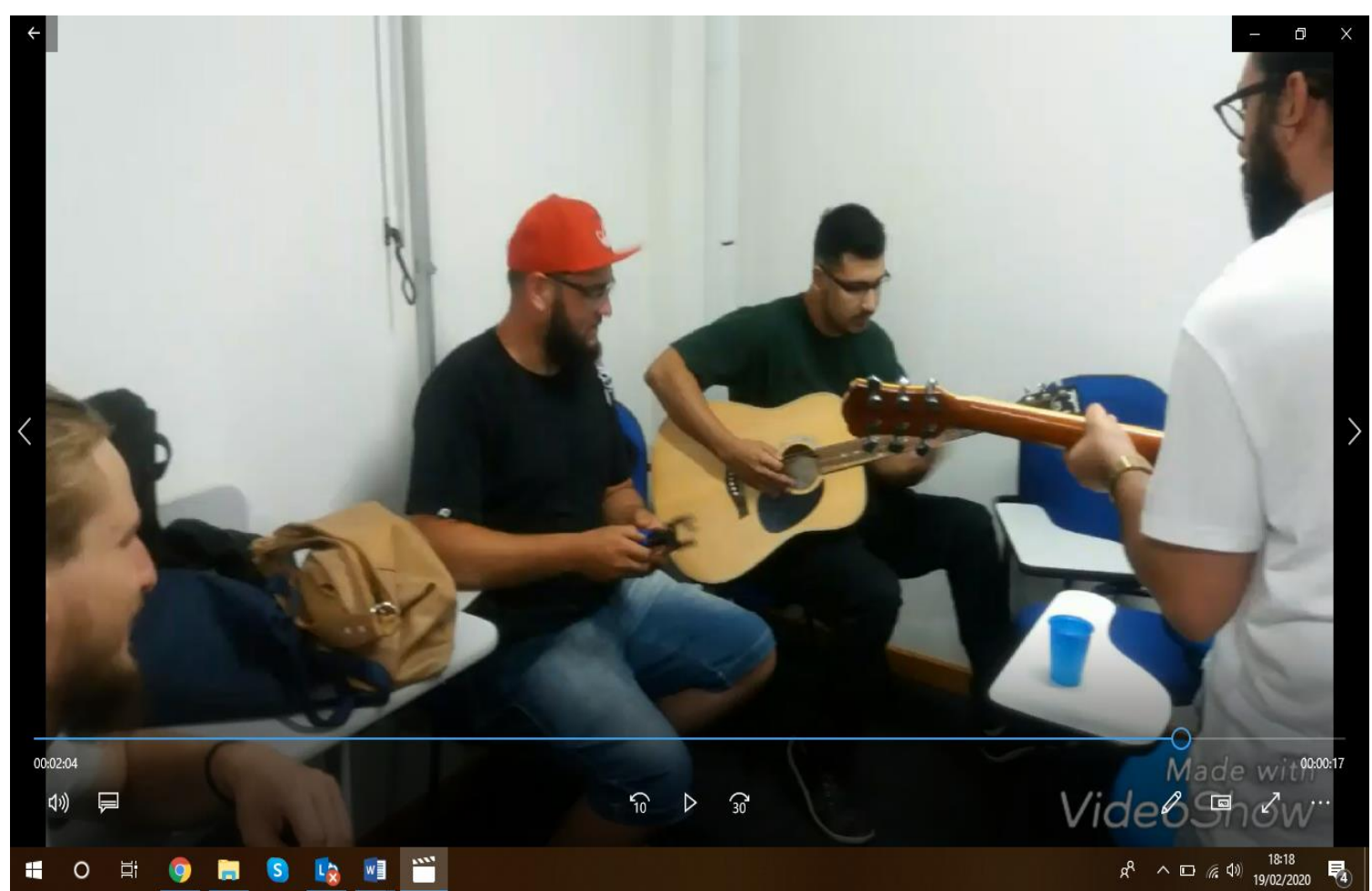

Fonte: grupo 9 - musicalização (2018).

Figura 3: Cerimonial da aula-evento

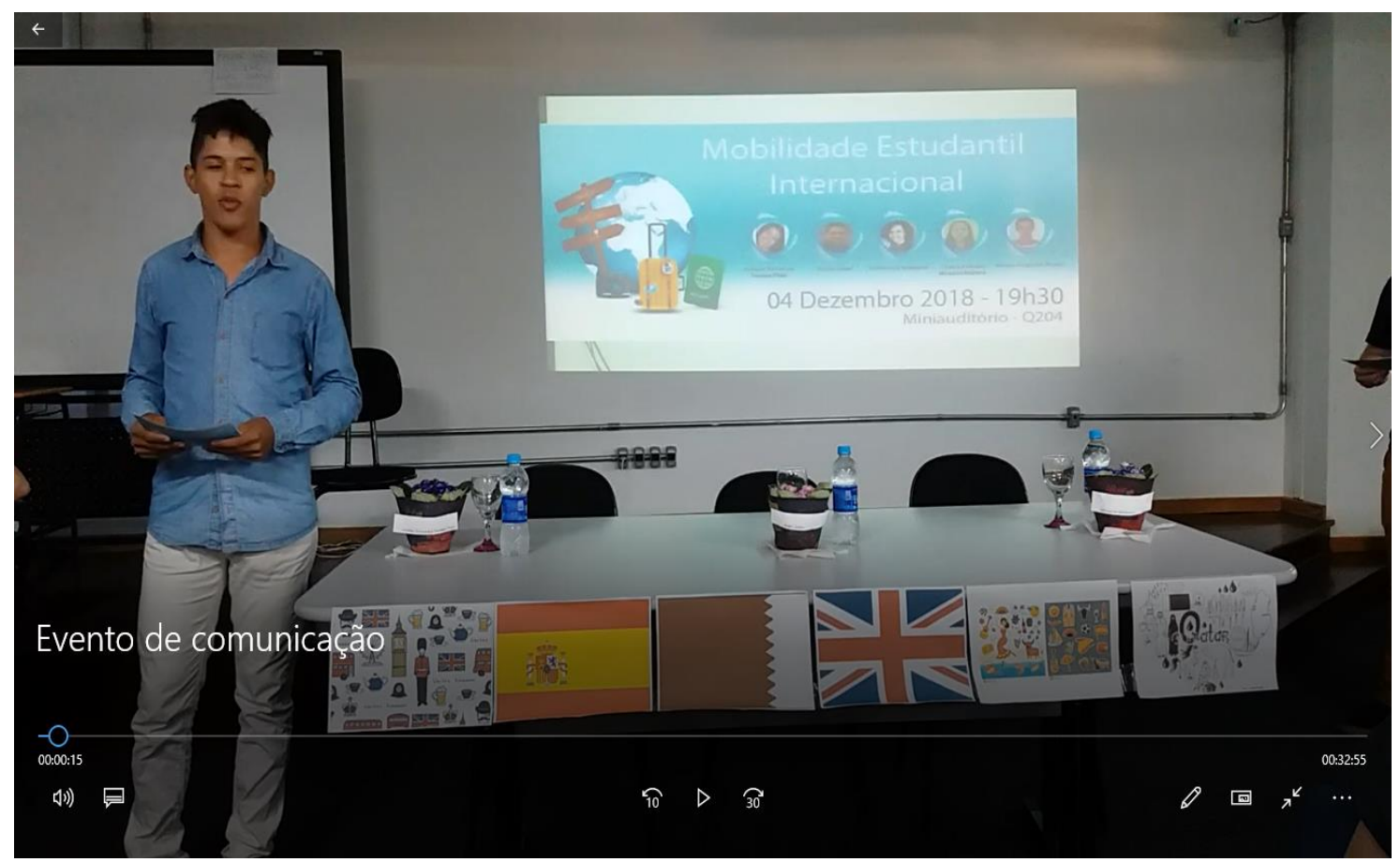

Fonte: grupo 8 - cerimonial (2018). 
Figura 4: Lembrancinhas aos palestrantes

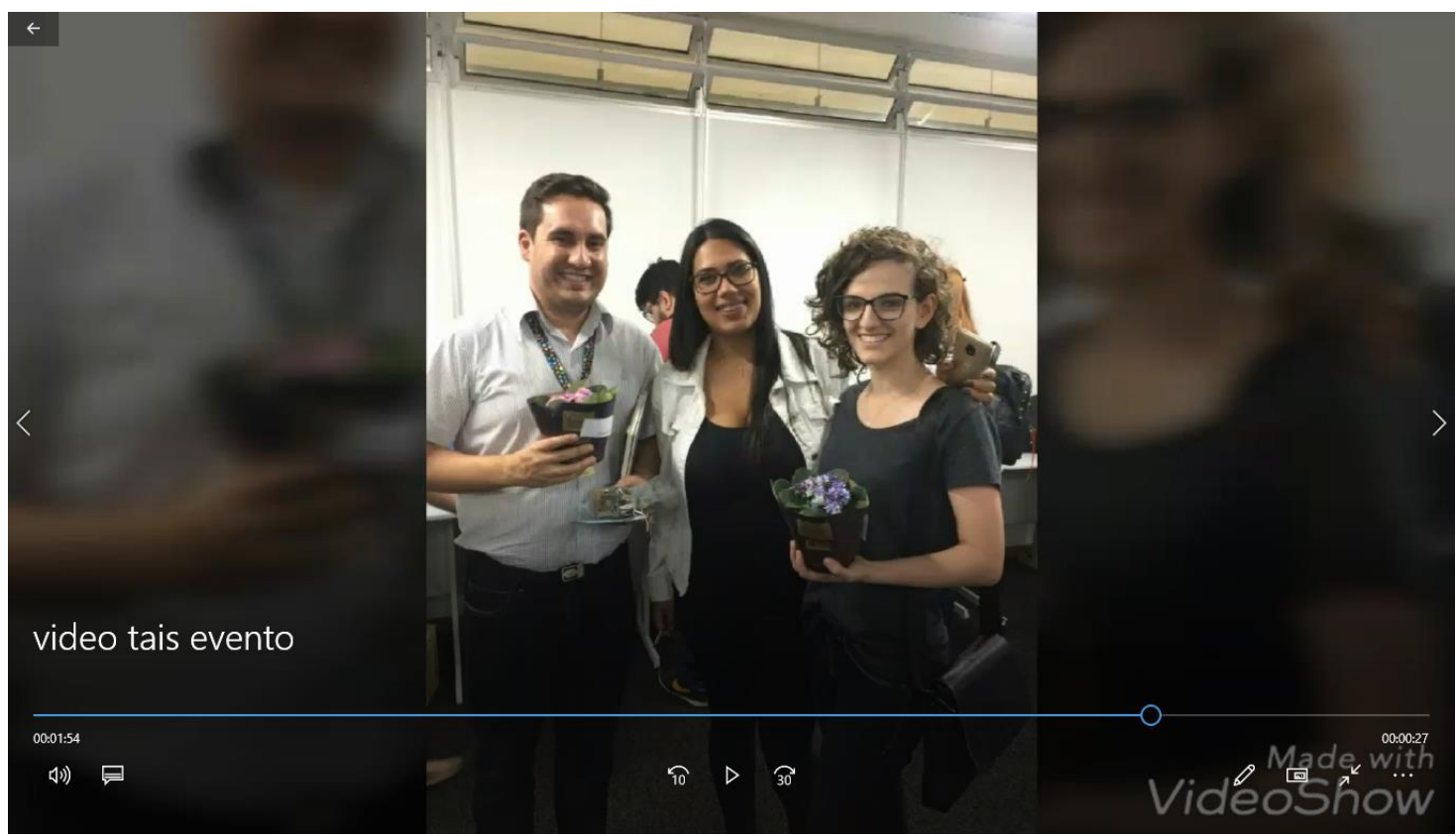

Fonte: grupo 2 - arrumação (2018).

Figura 5: Lembrança da aula-evento

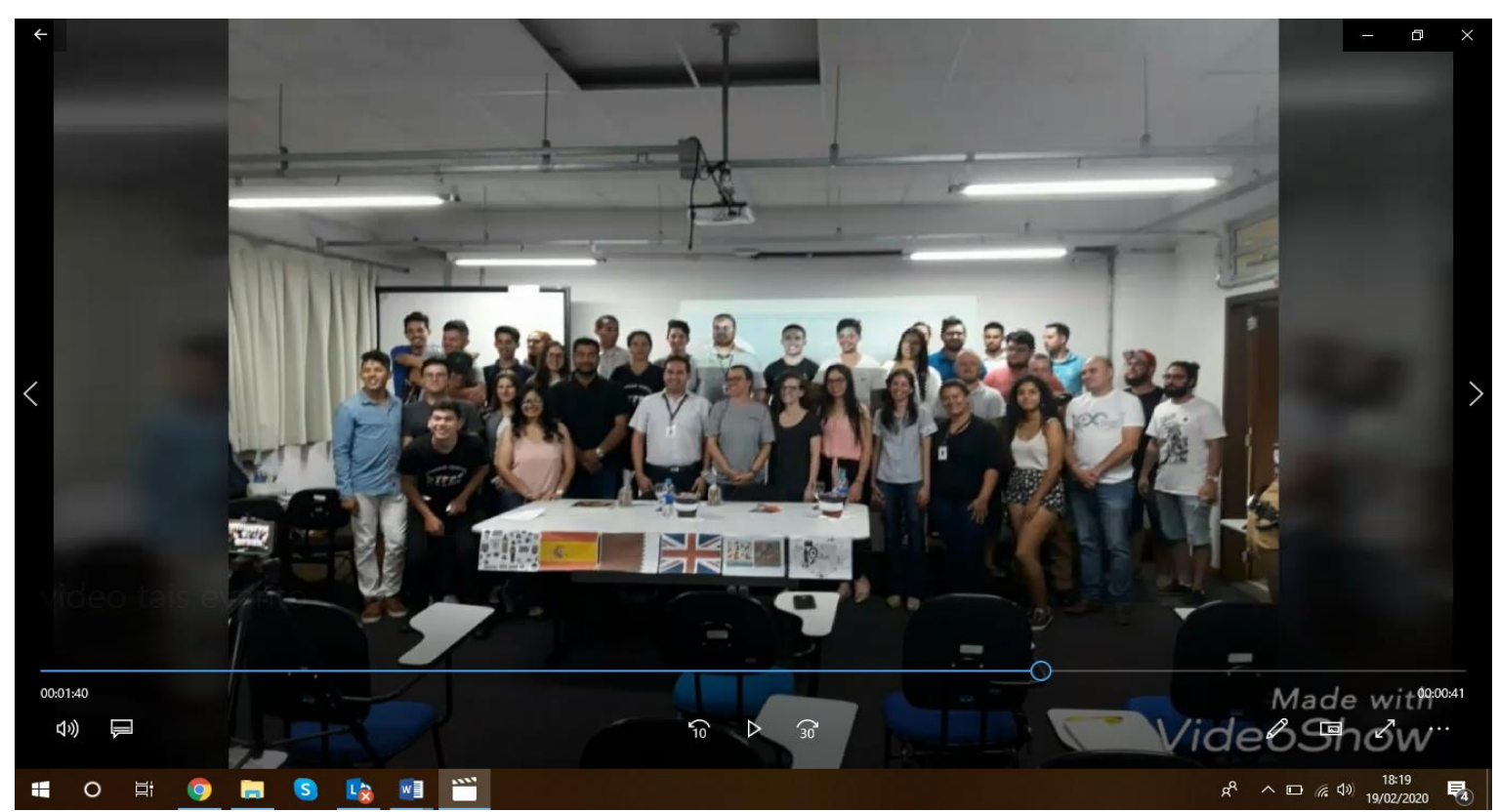

Fonte: grupo 3 - divulgação (2018).

Desse modo, terminadas as atividades da aula-evento, um dos acadêmicos que cursou esta disciplina resolveu ir além e pesquisar a questão da posição do sujeito através da perspectiva da $\mathrm{AD}$ foucaultiana em um semestre de iniciação científica voluntária no campus da UTFPR-FB. Seguindo os encaminhamentos damos prosseguimento apresentando como a pesquisa realizada pelo aluno foi desenvolvida. 


\section{Metodologia}

O processo de internacionalização começou desde a chegada dos europeus ao Brasil durante o descobrimento em 1500, trazendo suas crenças, culturas, idiomas e costumes. Durante esse período de desbravamento e independência do país até os dias de hoje percebemos a influência internacional no desenvolvimento das nações. A educação obtém grande parte dessas influências que contribuem diretamente para a evolução da pesquisa, ciência e tecnologia no país através dos programas de dupla diplomação e mobilidade estudantil. Esses programas têm o objetivo de proporcionar crescimento pessoal, educacional e profissional aos alunos de IES proporcionando-lhe experiências em outros países, e posteriormente trazendo para o Brasil e/ou levando para outros países novas formas de pensar, inovar e criar.

Este trabalho foi desenvolvido sob uma perspectiva qualitativa e tem como base teórica fundamental a análise do discurso foucaultiana. Discurso este que, como ressalta Revel (2005, p.37):

[...] designa, em geral, para Foucault, um conjunto de enunciados que podem pertencer a campos diferentes, mas que obedecem, apesar de tudo, a regras de funcionamento comuns. Essas regras não são somente lingüísticas ou formais, mas reproduzem um certo número de cisões historicamente determinada.

Nessa acepção, o discurso da internacionalização está atualmente envolvido nas IES e registra a cisão histórica que determina a inserção de editais de mobilidade internacional para acadêmicos/as e servidores/as.

O contato de estudantes de IES no exterior tem sido realidade no Brasil através desses programas. Na UTFPR-FB analisamos a posição sujeito de dois palestrantes disponível em um arquivo mais abrangente produzido pela turma de primeiro período do curso de Licenciatura em Informática com o tema: Mobilidade Estudantil. Sobre arquivo, Foucault (2015, p.98-99) afirma que:

[...] chamarei de arquivo não a totalidade de textos que foram conservados por uma civilização, nem o conjunto de traços que puderam ser salvos de seu desastre, mas o jogo de regras que em uma cultura, determinam o aparecimento e o desaparecimento de enunciados, sua permanência e seu apagamento, sua existência paradoxal de acontecimentos e de coisas.

Esse evento foi coordenado pela professora Carina Merkle Lingnau, apresentado como aulaevento com os convidados: Ivonete Terezinha Tremea Plein, Professor André Zuber, Sabrina de Medeiros, egressa do curso de Engenharia Ambiental da UTPFR-FB e Willian Felipe do Prado, também egresso do curso de Engenharia Ambiental. A turma do curso de informática e demais inscritos participaram como ouvintes e se tornaram responsáveis pela realização da aula-evento.

O evento foi composto por palestras e vídeos enviados por sujeitos que tiveram e estão tendo uma experiência educacional com esses programas. Para este artigo, verificamos na visão de Foucault, a 
posição de sujeito de dois palestrantes da aula-evento proposta para a análise. Esse recorte foi realizado no intuito de detalhar melhor as funções dos sujeitos verificados, pois para Foucault (2014, p.113)

[...] o sujeito do enunciado é uma função determinada, mas não forçosamente a mesma de um enunciado a outro; na medida em que é uma função vazia, podendo ser exercida por indivíduos, até certo ponto, indiferentes, quando chegam a formular o enunciado: e na medida em que um único e mesmo indivíduo pode ocupar, alternadamente, em uma série de enunciados, diferentes posições e assumir o papel de diferentes sujeitos.

Ainda para este autor, os primeiros mecanismos de construção do sujeito são aqueles que tentam fazer do homem um "sujeito objeto", ou seja, torná-lo politicamente dócil e economicamente útil na perspectiva de transparecer os processos que ocorrem em nossa sociedade, que fazem do homem, um sujeito preso a ela - sociedade - que passa a ser detentora de suas ações individuais. Para Foucault, é preciso ver o sujeito como alguém que pode ser um pai, um amigo, uma mãe, uma professora, ou seja, um sujeito capaz de assumir vários papeis na sociedade e não como um único objeto que pode ser manuseado pela própria sociedade. Foucault conceitua que o sujeito não é o indivíduo propriamente dito! Sujeito é aquele que não possui a subjetividade que é o espaço íntimo do indivíduo. Nesse sentido, buscamos verificar qual/quais posição/posições sujeito são ocupadas por um dos palestrantes envolvidos na aulaevento em questão.

\section{Resultados e análises}

As análises foram realizadas a partir dos links da aula-evento ${ }^{1}{ }^{2}$ ocorrida em dezembro de 2018. O palestrante 1 participou de um programa de Pós-Graduação no Catar, já o segundo palestrante vivenciou a dupla diplomação de Engenharia Ambiental na UTFPR-FB e na Universidade Tecnológica de Copiègne (UTC) na França.

A função sujeito mais ocupada no discurso do Palestrante 1 é a de sujeito acadêmico, enfatizando sua experiência no Catar como de aprendizado e imersão numa cultura nova e desconhecida. Outra posição que aparece bastante em seu discurso é a do sujeito turista que revela a cidade com costumes relativamente diferentes do Brasil, como por exemplo: o fato dos habitantes desta cidade terem dias específicos para as mulheres irem ao cinema, outros para homens, outros dias para a família. Além disso, ressaltou a receptividade do povo e a comida, que apesar de ser diferente, era muito boa. Analisando o discurso do palestrante 1 percebemos que ele assumiu papel de sujeito como acadêmico a maior parte do tempo, em busca de novas experiências, na perspectiva de agregar conhecimento em sua vida pessoal e acadêmica.

Como ilustração temos abaixo uma imagem da palestra realizada pelo palestrante 1 .

\footnotetext{
${ }^{1}$ Disponível em: https://www.youtube.com/watch?v=aiwveqebv6o. Acesso em: 21 fev. 2020.

${ }^{2}$ Disponível em: https://www.youtube.com/watch?v=yxbz5ji9eam\&t=6s. Acesso em: 21 fev. 2020.
} 
Figura 6: Palestrante 1 e jornal Catar

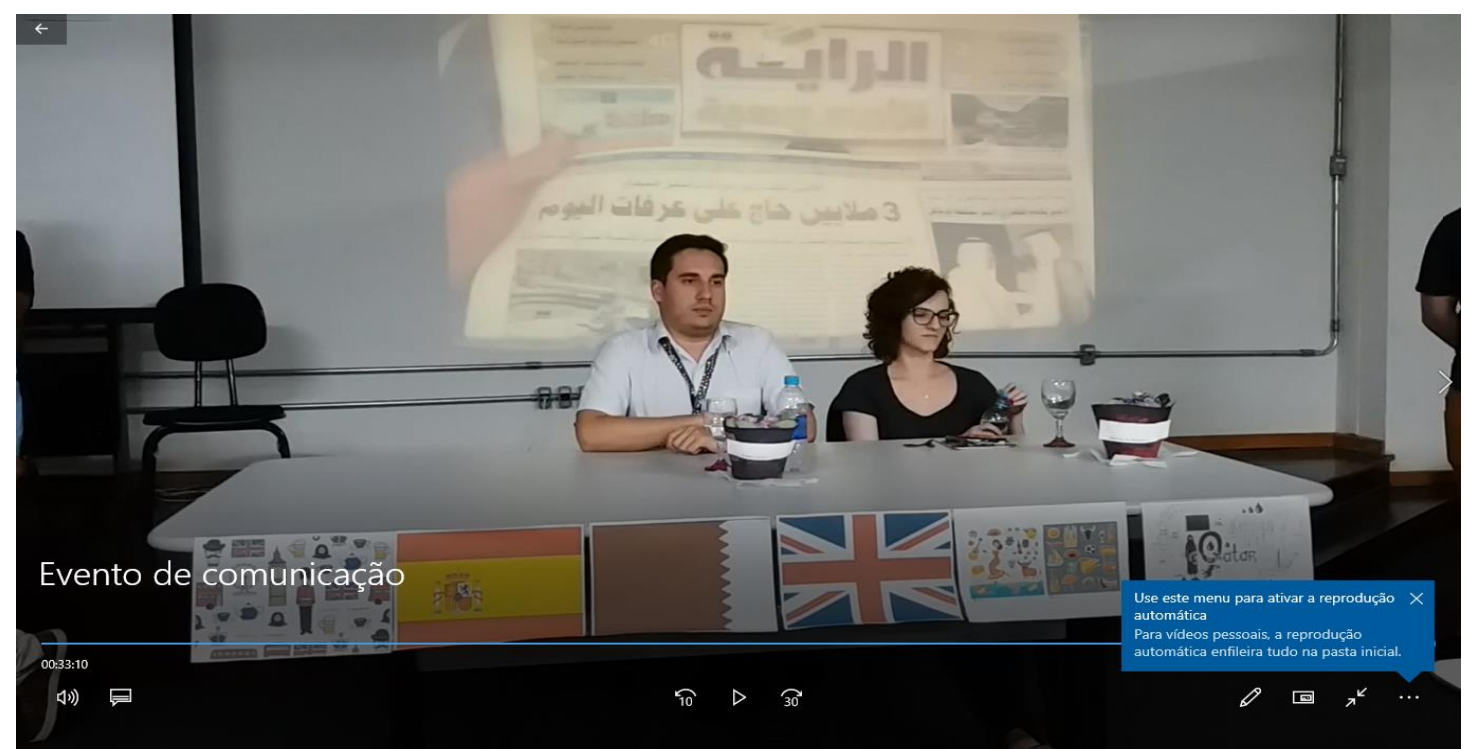

Fonte: grupo 3 - divulgação (2018).

Já o palestrante 2, que vivenciou a dupla diplomação de Engenharia Ambiental na UTFPR-FB e na Universidade Tecnológica de Copiègne (UTC) na França, ocupou mais a função sujeito profissional, muito embora tenha ocupado também a função acadêmico pois foi através dela que alcançou a posição sujeito profissional. Nessa perspectiva, o seu discurso esteve mais voltado ao resultado da sua experiência internacional, que foi a oportunidade de trabalho no exterior.

Figura 7: Palestrante 2 e colaboração em vídeo

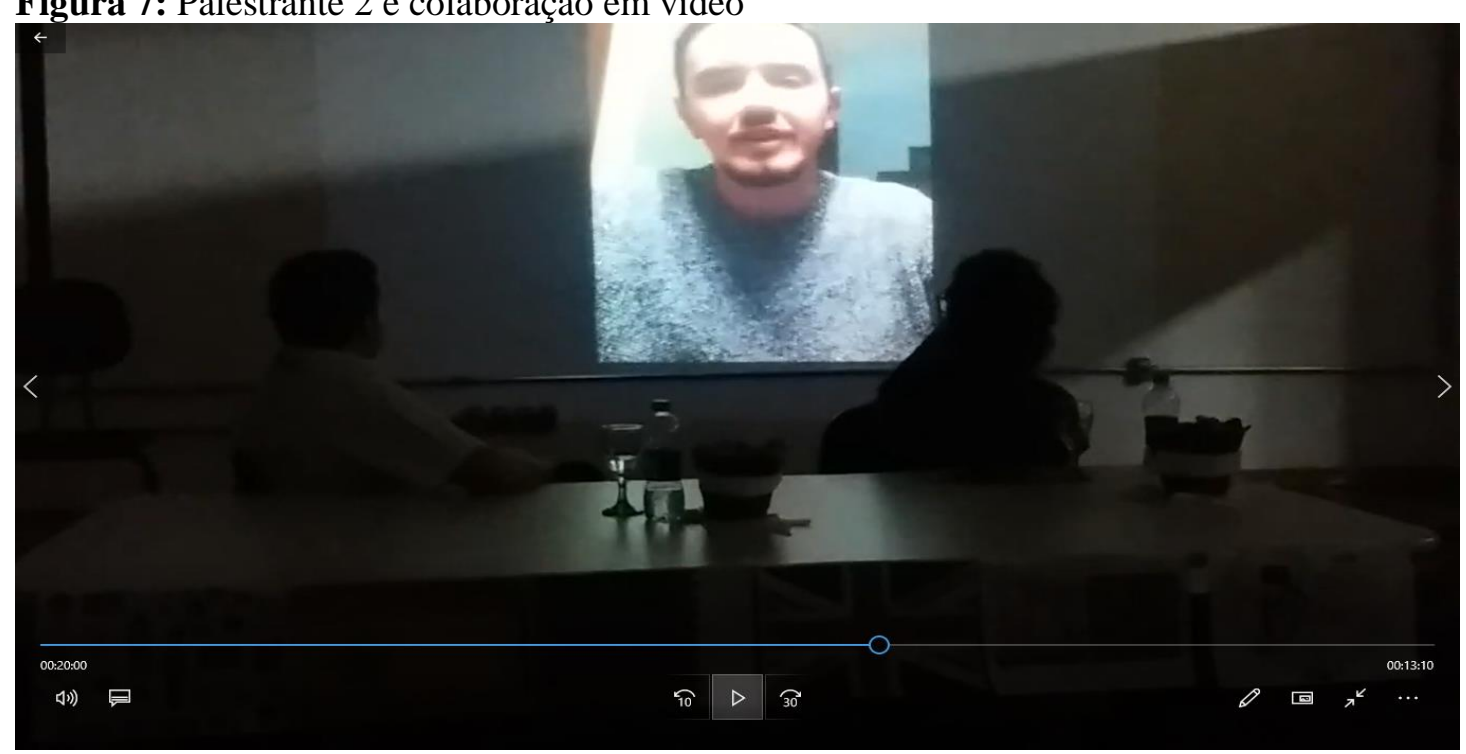

Fonte: grupo 3 - divulgação (2018). 
Sobre a posição do sujeito, Coracini (2007, p.17) afirma que:

[...] o sujeito da linguagem, para Lacan, lugar ou função discursiva, para Foucault, em ambas as visões, embora com pressupostos diferentes, o aspecto social se faz presente: o sujeito é também alteridade, carrega em si o outro, o estranho, que o transforma e é transformado por ele. É interessante lembrar que, se o sujeito é um lugar no discurso, heterogêneo na sua própria constituição e, por isso mesmo, fragmentado, cindido, o indivíduo (indiviso, uno) é um produto do exercício de poder disciplinar, daquilo que Foucault $(1975)^{3}$ denomina tecnologias de controle, totalidade ilusória que constitui o imaginário e, como tal, a identidade do sujeito: ilusão de inteireza, de totalidade, de coerência, de homogeneidade que torna cada um e todos socialmente governáveis e, portanto, idealmente sob o controle daquele(s) que ocupa(m) o lugar de autoridade legitimada.

Nesse sentido, o discurso da internacionalização apresentado pelas experiências dos dois palestrantes reflete o que Coracine (2007) considera como uma tecnologia de controle, uma vez que ambos estão vinculados a uma política governamental, viabilizada por uma "autoridade legitimada" - o Estado, que consequentemente atinge as IES e sua comunidade.

Assim, os dois palestrantes analisados representam sujeitos de um momento histórico absorvido pelo discurso da internacionalização, o qual, apesar de ser voltado principalmente para a perspectiva da internacionalização institucional, à medida que se vincula aos sujeitos, vincula, aos mesmos, diversos papeis sociais/funções que passam a configurar de modo diferenciado a posição específica desses sujeitos-indivíduos no discurso da internacionalização.

\section{Considerações finais}

O discurso da internacionalização se fez e se faz presente nas IES ao longo da história de nosso país. Nos últimos anos temos vivenciado esse discurso com mais intensidade a partir dos editais e do apoio das instituições de fomento estaduais e federais.

Esse discurso se faz presente nas grandes instituições assim como nas menores, foi desse modo que a turma de alunos de Comunicação Linguística da UTFPR-FB realizou a aula-evento sobre esse tema e que, posteriormente, veio a ser objeto de pesquisa do aluno de IC voluntário da UTFPR-FB.

Nessa direção percebemos que a partir das análises e dos conceitos que sustentaram essa pesquisa nem sempre os sujeitos preenchem as posições da mesma forma em um mesmo tempo histórico. As possibilidades de ocupar determinada posição em um discurso são mediadas por inúmeros elementos que colaboram para que o sujeito se posicione dessa ou de outra forma, impactando de modos diferentes na micro e macrosociedade que cerca esse sujeito.

\section{Referências}

${ }^{3}$ Coracini se refere ao texto de Foucault Surveiller et punir .Paris: Gallimard. 
COLUNAS TORTAS. O que é discurso? Uma abordagem Foucaultiana. Disponível em: https://colunastortas.com.br/o-que-e-discurso/. Acesso em 16 jul. 2019.

CORACINI, M.J. A celebração do outro: arquivo, memória e identidade: línguas (materna e estrangeira), plurilingüísmo e tradução. Campinas, SP: Mercado de Letras, 2007.

FOUCAULT, M. Microfísica do poder. Trad. Roberto Machado. 25ª.ed. Rio de Janeiro: Edições Graal, 2008.

FOUCAUlT, M. A arqueologia do saber: Tradução Luiz Felipe Baeta Neves. $8^{\text {a }}$.ed - Rio de Janeiro: Forense Universitária, 2014.

FOUCAULT, M. Ditos e escritos. Arqueologia das ciências e história dos sistemas de pensamento. MOTTA, Manoel Barros da (Org.). Tradução de Elisa Monteiro. Rio de Janeiro: Forense Universitária, 2015. v. 2.

MOROSINI, M. C. Internacionalização da educação superior no Brasil: a produção recente em teses e dissertações. Educação em Revista (online), 2017.

REVEL, J. Michel Foucault: conceitos essenciais. Tradução Maria do Rosário Gregolin, Nilton Milanez, Carlo Piovesani. São Carlos: Claraluz, 2005.

THOMPSON, P. O que é discurso? Uma abordagem Foucaultiana. Disponível em: $<<$ https://colunastortas.com.br/o-que-e-discurso/>>. Acesso em 24 maio de 2019.

Artigo recebido em: 22/06/2020. Artigo aceito em: 17/07/2020. 